(Asthma Research Centre), Universidade Federal de Santa Catarina, Santa Catarina, Brazil

\subsection{6/thoraxjnl-2013-204457.382}

Background The novel LABA olodaterol has 24-h bronchodilator activity.

Objective To evaluate the symptomatic benefit of olodaterol QD in patients with GOLD 2-4 COPD.

Methods In replicate, randomised, double-blind, placebo-controlled, parallel-group studies, patients with post-bronchodilator $\mathrm{FEV}_{1}<80 \%$ predicted normal and $\mathrm{FEV}_{1} / \mathrm{FVC}<70 \%$ received olodaterol $(5$ or $10 \mu \mathrm{g})$ QD via Respimat ${ }^{\circledR}$, formoterol $(12 \mu \mathrm{g})$ BID via Aerolizer ${ }^{\circledR}$ or placebo for 48 weeks (Study A: NCT00793624; Study B: NCT00796653). Patients continued to receive usual care background COPD maintenance therapy, including SAMA, LAMA, ICS and xanthines. In addition to $\mathrm{FEV}_{1}$-based primary end points, TDI and SGRQ after 24 weeks were identified as co-primary and key secondary symptomatic end points, respectively.

Results 904 (Study A) and 934 (Study B) patients were treated. In the primary analysis using a mixed model for repeated measures (MMRM; combined dataset), there was no significant difference in TDI focal score after 24 weeks for olodaterol or formoterol vs placebo. A post hoc analysis using pattern mixture modelling (PMM) to account for discontinued patients demonstrated statistical significance for olodaterol vs placebo. There were significant improvements in SGRQ total score with olodaterol, but not formoterol, vs placebo after 24 weeks using MMRM and PMM.

Conclusions Lung function improvements with olodaterol QD translated into symptomatic benefit in COPD patients receiving usual care background therapy.

\begin{tabular}{|c|c|c|c|c|c|}
\hline \multicolumn{6}{|c|}{ Abstract P230 Table 1.} \\
\hline \multicolumn{6}{|c|}{ Adjusted mean difference vs placebo after 24 weeks (combined dataset) } \\
\hline & \multicolumn{3}{|c|}{ TDI focal score } & \multicolumn{2}{|c|}{ SGRQ total score } \\
\hline & MMRM & & PMM & MMRM & PMM \\
\hline Olodaterol $5 \mu \mathrm{g}$ & $0.3^{*}$ & & $0.5^{\dagger}$ & $-2.8^{\dagger}$ & $-2.3^{\dagger}$ \\
\hline Olodaterol $10 \mu \mathrm{g}$ & $0.2^{*}$ & & $0.5^{\dagger}$ & $-3.4^{\dagger}$ & $-3.1^{\dagger}$ \\
\hline Formoterol $12 \mu \mathrm{g}$ & & $0.2^{*}$ & $0.4^{*}$ & $-1.2^{*}$ & $-1.2^{\star}$ \\
\hline
\end{tabular}

\section{P231 THE IMPACT OF INDACATEROL (ONBREZ®) ON THE DAILY LIVES AND HEALTH STATUS OF PATIENTS WITH COPD: INTERIM RESULTS}

${ }^{1} \mathrm{PW}$ Jones, ${ }^{2} \mathrm{D}$ Saralaya, ${ }^{3} \mathrm{JB}$ Morjaria, ${ }^{4} \mathrm{~T}$ Quadrino, ${ }^{5} \mathrm{~A}$ Qurbain; ${ }^{1}$ St George's University of London, London, UK; ${ }^{2}$ Bradford Teaching Hospitals NHS Foundation Trust, Bradford, UK; ${ }^{3} \mathrm{Hull}$ and East Yorkshire NHS Hospital Trust, Hull, UK; ${ }^{4} \mathrm{pH}$ Associates Ltd, Marlow, UK; ${ }^{5}$ Novartis Pharmaceuticals Ltd, Frimley, UK

10.1136/thoraxjnl-2013-204457.383

Introduction The GOLD guidelines recommend that the COPD Assessment Test $(\mathrm{CAT})^{1}$ can be used in guiding and optimising therapy, however there is little evidence on its use in monitoring treatment. Aim We have conducted a 6-month prospective observational study describing the impact of COPD on daily life, following the initiation of maintenance indacaterol, a once-daily long-acting beta-agonist.

Method Subjects from 39 UK GP practices (April 2012 to May 2013) with a diagnosis of COPD and were newly-prescribed indacaterol for routine COPD management, either as maintenance mono-therapy or add-on therapy to long-acting muscarinic antagonists (LAMA) were recruited. Here we present interim results of completed CAT and a descriptive Daily Life Impact Questionnaire (DLIQ), developed for specifically for the study, at treatment initiation and 6-8 weeks. Further assessments will be made at 6 months, when treatment changes in addition to indacaterol will be recorded.

Results One hundred and three subjects (61 males, 42 females), with a mean age of 67 years (range 44-86) and a median baseline FEV1\% predicted of 61\% $(n=100$; IQR 51-70\%) were recruited. Median time from diagnosis to indacaterol initiation was 6 months (IQR 0-37). Of the $86(83.5 \%)$ subjects evaluated for change in CAT score, $65(76 \%)$ had a reduction (i.e. improved health status), 18 (21\%) increased and 3 (3\%) remained the same (Figure 1); with a mean overall change of 4.1 ( $\mathrm{SD} \pm 5.6 ; \mathrm{p}<0.001)$. Fifty-nine (69\%) subjects had a $\geq 2$ point (clinically significant) reduction in CAT score. Ninety-two patients completed the DLIQ; 42 (46\%) patients reported an improved ability to perform activities important to them, which had previously been rated as being challenging (e.g. walking, gardening, housework).

Conclusion The CAT appears responsive to treatment for COPD with indacaterol when assessed in routine practice and the average size of improvement was large. Alongside this mean improvement, nearly half of patients reported the ability to do more activities that previously they had found difficult. These initial results require further confirmation when full results are available at 6 months.

\section{REFERENCES}

1. Jones PW, Harding G, Berry P, Wiklund I, Chen WH, Kline Leidy N. Development and first validation of the COPD Assessment Test. Eur Respir J 2009;34:648-54

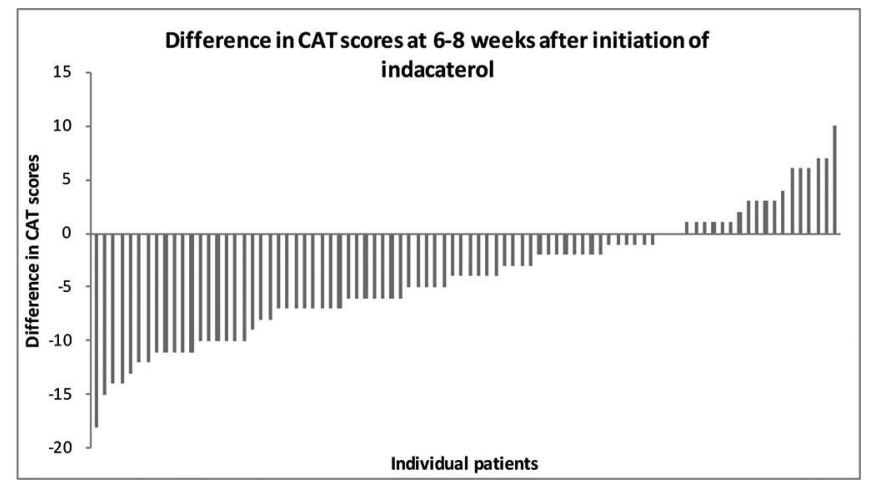

Abstract P231 Figure 1. The impact of indacaterol (Onbrez) on the daily lives and health status of patients with COPD: interim results.

\section{P232 ONCE-DAILY CO-ADMINISTRATION OF GLYCOPYRRONIUM AND INDACATEROL VIA BREEZHALER ${ }^{\circledR}$ DEVICE IMPROVES LUNG FUNCTION AND SYMPTOMS IN PATIENTS WITH COPD VERSUS INDACATEROL ALONE: THE GLOW6 STUDY}

${ }^{1} \mathrm{~W}$ Vincken, ${ }^{2} \mathrm{~J}$ Aumann, ${ }^{3} \mathrm{D}$ Jack, ${ }^{4} \mathrm{H}$ Chen, ${ }^{4} \mathrm{M}$ Henley, ${ }^{5} \mathrm{P}$ Goyal; ${ }^{1}$ Respiratory Division, University Hospital Brussels, University of Brussels, Brussels, Belgium; ${ }^{2}$ Department of Respiratory Diseases, Virga Jesse Ziekenhuis, Hasselt, Belgium; ${ }^{3}$ Novartis Horsham Research Centre, Horsham, UK; ${ }^{4}$ Novartis Pharmaceuticals Corporation, East Hanover, NJ, USA; ${ }^{5}$ Novartis Pharma AG, Basel, Switzerland

10.1136/thoraxjnl-2013-204457.384 
Introduction To benefit symptomatic patients with moderate-tosevere COPD not managed by single bronchodilator, COPD management strategies recommend combining bronchodilators with different mechanisms. We compared, once-daily dual bronchodilation by co-administration of the long-acting muscarinic antagonist (LAMA) glycopyrronium 50 $\mu$ g (GLY) and the long-

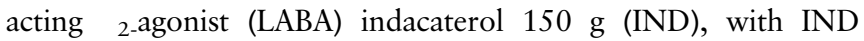
$150 \mu \mathrm{g}$ monotherapy.

Methods In this randomised, multicentre, placebo-controlled, double-blind, parallel-group study, patients with moderate-tosevere COPD were administered with GLY + IND or IND + placebo $\left(1: 1\right.$; all delivered via Breezhaler ${ }^{\circledR}$ device) for 12 weeks. We assessed lung function, dyspnoea (via the transition dyspnoea index [TDI]), patient-reported symptoms, and safety and tolerability over 12 weeks.

Results Of the 449 patients randomised (GLY + IND $[\mathrm{n}=226]$; IND $[\mathrm{n}=223]), 94.0 \%$ completed the study. At Week12, GLY + IND demonstrated a statistically significant improvement in mean trough forced expiratory volume in one second $\left(\mathrm{FEV}_{1}\right)$ over IND (least squares mean treatment difference [Td]: $64 \mathrm{~mL} ; \mathrm{p}<0.001)$. Significantly greater improvements in $\mathrm{FEV}_{1}$ area under curve from $30 \mathrm{~min}$ to $4 \mathrm{~h}\left(\mathrm{FEV}_{1} \mathrm{AUC}_{30 \mathrm{~min}-4 \mathrm{~h}}\right)$ and trough forced vital capacity were observed with GLY + IND vs IND on Day1 (Td: $105 \mathrm{~mL}, 112 \mathrm{~mL}$, respectively) and at Week12 (Td: $111 \mathrm{~mL}, 93 \mathrm{~mL}$, respectively), all $\mathrm{p}<0.01$. GLY + IND demonstrated significant improvements in inspiratory capacity versus IND at most timepoints on Day1 and Week12 (Td: 59 to $159 \mathrm{~mL}$ ). GLY + IND significantly improved TDI total score versus IND (Td: $0.49, \mathrm{p}=0.037)$ and a higher proportion of patients on GLY + IND achieved a clinically meaningful improvement ( $\geq 1$ point) versus IND at Week12 (odds ratio 1.97 favouring GLY + IND; $p=0.004)$. GLY + IND was also associated with significantly greater improvements in mean daytime respiratory symptom score and the percentage of days being able to perform usual daily activities vs IND over 12 weeks of treatment (Td: -0.1 and 6.2, respectively; both $\mathrm{p}<0.05$ ). The overall incidence of adverse events (AEs) and serious AEs (SAEs) was comparable for the GLY + IND and IND groups (AEs: $37.6 \%$ vs $34.1 \%$; SAEs: $2.2 \%$ vs $2.3 \%$, respectively).

Conclusion In patients with moderate-to-severe COPD, compared with indacaterol monotherapy, once-daily co-administration of glycopyrronium and indacaterol delivered via Breezhaler ${ }^{\circledR}$ device provided superior improvements lung function and early post-dose bronchodilation (from Day1), dyspnoea, symptoms and activities, without adversely affecting safety and tolerability.

\section{P233 EFFICACY AND SAFETY OF ONCE-DAILY GLYCOPYRRONIUM COMPARED WITH BLINDED TIOTROPIUM IN PATIENTS WITH COPD: THE GLOW5 STUDY}

${ }^{1} \mathrm{KR}$ Chapman, ${ }^{2} \mathrm{~K}$ Beeh, ${ }^{3} \mathrm{ED}$ Bateman, ${ }^{2} \mathrm{~J}$ Beier, ${ }^{4} \mathrm{AD}$ D'Urzo, ${ }^{5} \mathrm{R}$ Nutbrown, ${ }^{6} \mathrm{H}$ Chen, ${ }^{6} \mathrm{M}$ Henley, ${ }^{5} \mathrm{~T}$ Overend, ${ }^{6} \mathrm{P}$ D'Andrea; ${ }^{1}$ Toronto Western Hospital, Toronto, Canada; ${ }^{2}$ Respiratory Research Institute, Wiesbaden, Germany; ${ }^{3}$ University of Cape Town, Cape Town, South Africa; ${ }^{4}$ University of Toronto, Ontario, Canada; ${ }^{5}$ Novartis Horsham Research Centre, Horsham, UK; ${ }^{6}$ Novartis Pharmaceuticals Corporation, East Hanover, NJ, USA

\subsection{6/thoraxinl-2013-204457.385}

Background Glycopyrronium, a once-daily long-acting muscarinic antagonist (LAMA), has demonstrated a similar efficacy and safety profile to open-label tiotropium in patients with moderate-to-severe chronic obstructive pulmonary disease (COPD). ${ }^{1}$ The GLOW5 study compared the efficacy and safety of glycopyrronium with blinded tiotropium.

Methods In this multicentre, 12-week, blinded study, patients $\geq$ 40 years with moderate-to-severe COPD (post-bronchodilator $\mathrm{FEV}_{1} \geq 30 \%$ and $<80 \%$ of the predicted normal, post-bronchodilator $\mathrm{FEV}_{1} / \mathrm{FVC}<0.70$ ) and a smoking history of $\geq 10$ pack-years were randomised to glycopyrronium $50 \mu \mathrm{g}$ (via Breezhaler ${ }^{\circledR}$ device) or tiotropium $18 \mu \mathrm{g}$ (via HandiHaler ${ }^{\circledR}$ device). The primary objective was to demonstrate non-inferiority of glycopyrronium versus tiotropium for trough $\mathrm{FEV}_{1}$ at Week 12 (non-inferiority margin: $-50 \mathrm{~mL}$ ). Other endpoints included $\mathrm{FEV}_{1}$ area under the curve from 0 to 4 hours $\left(\mathrm{AUC}_{0-}\right.$ $4 \mathrm{hr}$ ) on Day 1, Transition Dyspnoea Index (TDI), St George's Respiratory Questionnaire (SGRQ), rescue medication use, exacerbation rate, safety and tolerability.

Results Of the 657 patients randomised, (glycopyrronium [n = 327]; tiotropium [ $\mathrm{n}=330]$; mean age: 63.5 years, mean post-bronchodilator $\mathrm{FEV}_{1}: 53.5 \%$ predicted), 95.9\% completed the study. Glycopyrronium demonstrated non-inferiority to tiotropium for trough $\mathrm{FEV}_{1}$ at Week 12 (Least Squares Mean $[\mathrm{LSM}]=1.41 \mathrm{~L}$ for both the groups; 95\% confidence interval [CI]: $-0.032,0.031 \mathrm{~L})$. Glycopyrronium had a rapid onset of bronchodilation in the morning as demonstrated by a higher $\mathrm{FEV}_{1} \mathrm{AUC}_{0-4 \mathrm{hr}}$ on Day 1 compared to tiotropium (LSM treatment difference $[\mathrm{Td}]=58 \mathrm{~mL} ; \mathrm{p}<0.001)$. At Week 12, TDI total score $(\mathrm{Td}=-0.188 ; \mathrm{p}=0.385)$, SGRQ total score $(\mathrm{Td}=0.65 ; \mathrm{p}=0.488)$ and percentage of days with no rescue medication use $(\mathrm{Td}=-1.5 ; \mathrm{p}=0.528)$ were comparable between the groups. No significant treatment difference was observed with respect to rate of moderate/severe COPD exacerbations per year (glycopyrronium 0.38 versus tiotropium 0.35 [rate ratio $=1.10,95 \%$ CI: $0.62,1.93] ; \mathrm{p}=0.754$ ). Overall, the incidence of adverse events was similar in the glycopyrronium $(40.4 \%)$ and tiotropium (40.6\%) groups.

Conclusion Glycopyrronium and blinded tiotropium showed similar improvements in lung function, dyspnoea, health status, exacerbation rate and rescue medication use, with a similar safety and tolerability profile. Onset of bronchodilation with glycopyrronium was significantly more rapid following the first dose.

\section{REFERENCE}

1. Kerwin, E. et al. Eur Resp J 2012;40:1106-1114.

\section{P234 QVA149 ONCE DAILY IMPROVES LUNG FUNCTION, DYSPNOEA AND HEALTH STATUS INDEPENDENT OF PRIOR MEDICATIONS AND DISEASE SEVERITY: THE SHINE STUDY}

${ }^{1} \mathrm{KR}$ Chapman, ${ }^{2} \mathrm{ED}$ Bateman, ${ }^{3} \mathrm{~N}$ Gallagher, ${ }^{4} \mathrm{H} \mathrm{Hu},{ }^{4} \mathrm{D}$ Banerji; ${ }^{1}$ Asthma and Airway Centre, University Health Network, Toronto Western Hospital, Toronto, Canada; ${ }^{2}$ Department of Medicine, University of Cape Town, Cape Town, SA; ${ }^{3}$ Novartis Horsham Research Centre, West Sussex, UK; ${ }^{4}$ Novartis Pharmaceuticals Corporation, East Hanover, NJ, USA

\subsection{6/thoraxjnl-2013-204457.386}

Introduction QVA149 is a novel, inhaled, once-daily, fixed-dose combination of the long-acting $\beta_{2}$-agonist (LABA) indacaterol and the long-acting muscarinic antagonist (LAMA) glycopyrronium (NVA237) in development for the maintenance treatment of chronic obstructive pulmonary disease (COPD). The SHINE study compared the effects of QVA149 $110 / 50 \mu \mathrm{g}$, indacaterol $150 \mu \mathrm{g}$, glycopyrronium $50 \mu \mathrm{g}$, tiotropium $18 \mu \mathrm{g}$ and placebo in 